\title{
DUTIES OF PARTIES TOWARDS EFFECTIVE HEALTH AND SAFETY MANAGEMENT DURING DESIGN AND CONSTRUCTION
}

\author{
Abatan, Stephen Olasunkanmi, Oke, Oluyemi E, \\ Department of Architectural Technology \\ Federal Polytechnic, Ede, Osun State, Nigeria
}

\author{
Bankole, Omolara R, BabarindeRacheal A. \\ Department of Estate management \\ Federal Polytechnic, Ede, Osun State, Nigeria
}

\begin{abstract}
Building and construction industry in Nigeria has tremendously grown in the recent past owing to its contributions to national economy. Healthy and safety is an important aspect of the industry, yet, it remains unsatisfactory in terms of frequent occurrence of accidents and ill health on construction sites. Moreover, the occurrence of accidents on construction sites usually leads to site closure for investigation, loss of man/machine hours, loss of output, loss of corporate reputation, payment of burial expenses/compensation/insurance claims for the dead. These ugly incidents have necessitated the need for an effective health and safety management in the industry. This paper therefore analyzes the global situations of health and safety in the industry, examines the sources of accidents and ill health during construction and also investigates the health and safety management system and its challenges. The paper further analyzes the duties of parties involved in management of health and safety, communication of health and safety among the parties and assesses the strategies used in communication during design and construction stages.
\end{abstract}

Keywords - Accidents; Construction industry; Design stages; Health and safety; III health

\section{INTRODUCTION}

The construction industry is an important part of the economy in many countries and is often seen as a driver of economic growth by contributing to Gross Domestic Product (GDP)especially in developing countries(Phoya 2012). The products of the industry are used by other industrial sectors for the production of other goods and services. For instance, construction of buildings, development of feeder roads, commercial infrastructures, electricity and water supply. Construction works provide opportunities for employment for a wide range of people skilled, semi-skilled and unskilled, owing to its relatively labour intensive nature.

Despite its importance and attractiveness, construction industry is considered risky with frequent and high accidents rates, ill health problems to workers, practitioners, end users and the public (Kadiri et al, 2014). Construction industry has a reputation for having many accidents, with construction workers approximately three times more likely to suffer from fatal injuries than those in other sectors. However, when compared with other industries, the construction industry has earned the reputation of being a dangerous or highly hazardous industry because the industry has a poor health and safety performance record compared to other industries all over the world. Every year many people fall victim to injury, harm and even death caused by accidents on construction sites.

Many building construction activities are inherently risky to health and safety such as working at height, working underground, working in confined spaces and close proximity to falling materials, handling loads manually, handling hazardous substances, noises, dusts, using plant and equipment, fire and exposure to live cables. Moreover, deaths, permanent disabilities and severe injuries have been on the increase for building workers through major accidents and poor working conditions. However, the occurrence of accidents usually leads to site closure for investigation, loss of man/machine hours, loss of output, loss of corporate reputation, payment of burial expenses/compensation/insurance claims for the dead. These ugly incidents have necessitated the need for a positive health 


\section{International Journal of Engineering Applied Sciences and Technology, 2021 \\ Vol. 6, Issue 4, ISSN No. 2455-2143, Pages 40-54 \\ Published Online August 2021 in IJEAST (http://www.ijeast.com)}

and safety culture in the industry, since the associated costs of fatalities are immense to the individual, the employer and the society in general.

Certainly in every organization, safety of workers should be considered number one priority, it is when these workers are in good state of mind and physically healthy that works can go on smoothly on construction sites, hence the need for integrating safety culture into the organizational system.

\section{GLOBAL SITUATION OF HEALTH AND SAFETY IN BUILDING AND CONSTRUCTION INDUSTRY}

The issues of accidents and ill health problems in building and construction industry are of grave concern for both practitioners and researchers all over the world (Alhajeri, 2011; Phoya, 2012; Dadzie, 2013; Muiruri and Mulinge, 2014). Thus, the industry has been regarded as the most hazardous place in which to work with a high level of health and safety risks (ILO, 2011). The International Labour Organization (ILO) estimates that at least 60,000 fatal accidents happen in a year on construction sites around the world, which is one in six of all fatal work related accidents. Furthermore, it has been acknowledged that $25-40 \%$ of fatalities in the world's occupational settings are contributed by construction (ILO, 2011). In the same vein, occupational health and safety statistics presented by different researchers revealed that, the injury and fatality rate in construction projects is very high in comparison with other sectors of industry in the majority of countries (Alhajeri, 2011; Phoya, 2012; Dadzie, 2013).

In Europe, for example, the construction industry employs about $10 \%$ of the total industrial workforce. European construction industry accounts for $30 \%$ of all workrelated accidents and injuries (Kawuwa, Adamu, Shehu \&Abubakar, 2018). The risk of a fatality in the United Kingdom construction industry is five times higher than that experienced in the same nation's manufacturing industry. In the United State, it accounts for $20 \%$ of all fatal accidents, yet it employs only $5 \%$ of the total working population (Kawuwa et al., 2018).

In Japan, construction accidents account for 30\% $40 \%$ of the overall total of industrial accidents, with the total being 50\% in Ireland (ILO, 2011). It was also confirmed that construction fatal accidents account for 59\% of total fatal accidents in all industries over Singapore. Hong Kong recorded a total of 3,001 convictions for health and safety offences with a total fine of $\$ 17$ million in 2003. Out of this figure, 1,382 convictions with a total fine of $\$ 1$ million were related to construction site alone (Agwu and Olele, 2014). In Italy, the fatal accidents in the field of construction represent $25 \%$ of the total accidents occurring in the industry (Baldacconi and Santis, 2000). In New South Wales, Australia, the inherent hazards and associated risks of the construction industry are reflected in its high incidents and frequency injury rates demonstrated by the fact that in 1998/1999, construction had the third highest number of incidents, based on compensated injuries.

Other research works conducted in developing countries corroborate evidence of this relatively high proportion of accidents on construction sites. In developing countries, construction industry has performed far below the expectation in the areas of health and safety because it involves more workers per activity on site and due to absence of any stringent safety and construction laws. More workers are therefore exposed to hazards (Kheni, 2008). ILO (2011) attributes the poor health and safety records in construction industry within the developing countries to high proportion of small firms; high number of self-employed workers; variety and comparatively short life of construction sites and large proportion of seasonal and migrant workers. Kawuwa et al., (2018) found that, in most developing countries, there are no training programs for staff and workers; therefore, no orientation for new staff or workers is conducted; hazards are not pointed out; and no safety meetings are held. Employees are expected to learn from their own mistakes and experience. In Ghana, it was reported that the construction industry recorded 902 accident cases comprising 56 fatal accidents and 846 non-fatal accidents in year 2000 (Danso, 2005). In that same report, it was indicated that Kumasi (the regional capital of Ashanti) alone recorded 124 construction accident deaths from 1999 to 2004. Furthermore, Laryea and Mensah (2010) revealed a poor state of health and safety on Ghanaian construction sites.

The situation is quite pathetic in Nigeria because there is no existing functional legislation to that effect. There is no reliable data on accident cases on construction sites in Nigeria, because contractors do not report accidents at appropriate ministry nor keep proper records on accidents. Occupational health and safety regulatory system in the country does not encourage mandatory reporting of accidents (Idoro 2008). A study by Ezenwa (2001) over a 10-year period (1987-1996) of fatal injuries reported to the Inspectorate Division of Federal Ministry of Labour and Productivity indicated that Nigeria's construction industry is responsible for about $7.5 \%$ of all occupational accidents, $49.5 \%$ of these injuries were fatal, $12.2 \%$ of partial disabilities and $7.4 \%$ of 


\section{International Journal of Engineering Applied Sciences and Technology, 2021 \\ Vol. 6, Issue 4, ISSN No. 2455-2143, Pages 40-54 \\ Published Online August 2021 in IJEAST (http://www.ijeast.com)}

minor injuries (Umeokafor, Isaac, Jones \& Umeadi,2014). The construction industry has been ranked the second highest in terms of injuries, after mine. In fact between 1990 and 1994, the overall fatality rate as recorded is $22 \%$ of the above reported cases. This explains why Idoro (2011) in a study of 42 construction contractors in Nigeria, found that in 2006 the best safety record is 5 injuries per worker and 2 accidents per 100 workers.

Findings from studies carried out to assess the causes of these accidents have pointed to poor health and safety management in building and construction industry (Kwofie, 2015; Akunyumu, 2016).

\section{SOURCES OF ACCIDENTS AND ILL-HEALTH PROBLEMS ON CONSTRUCTION SITES}

In order to understand the sources of accidents and subsequent injuries, researchers have attempted to develop theories of why accidents occur. Accidents are viewed as originating from a technical or human error. The sources are categorized into behavioural and environmental factors. Behavioural factors include lack of knowledge about safety rules, engaging an inexperienced workforce and lack of respect for safety. Environmental factors include worksite hazards and procedures that contribute to injuries. Furthermore, Rahim, Hamid, Zaimi, Majid \& Singh(2008) carried out a survey in Malaysia to identify the causes of accidents on construction sites and found that unsafe methods, including incorrect procedures, knowledge level and disobeying procedures are the most frequent reasons for accidents on construction sites. In addition to these causes, Holt (2001) argued that secondary sources of accidents centered on management pressures, such as financial restrictions, lack of commitment, inadequate policy and standards, deficient knowledge and information, restricted training and task selection and poor quality control systems. Holt (2001) further emphasized that incomplete structural connections, temporary facilities, tight work areas, varying work surface conditions, continuously changing work-sites, multiple operations and crews working in close proximity are common causes of construction-related deaths and injuries.

According to Okoye and Okolie (2014), unsafe conditions exist on many sites, both large and small, and laborers are subjected to numerous hazards, no training programs for the staff and workers exist; therefore, no orientation for new staff or workers is conducted, hazards are not pointed out, and no safety meetings are held. Employees are required to learn from their own mistakes or experience. In addition, lack of medical facilities, shanty housing, and substandard sanitation tend to exist on remote projects. While working on site, workers undertake a number of risk and the following problem areas are common: While excavating in deep trenches (with no proper shoring or bracing), accidents due to cave-ins often occur; concreting is done mainly by labourers and cements burns due to the unavailability of protective gloves and boots are common; workers fall from heights due to weak scaffolding and the unavailability of safety belts. Workers sustain injuries on the head, fingers, eyes, feet, and face due to absence of personal protection equipment.

To conceptualize the above sources of accidents and ill-health problems on construction sites, it is observed that the causes of construction accidents can generally be classified into the five most influential factors namely, site conditions, equipment and materials, human, management and job factors. Figure 1represents a summary of the sources of health and safety risk on construction site. It indicates the five main sources of accidents on construction sites. The sources include site conditions such as the nature and physical layout of the work, location and weather; equipment and materials specification such as paint and asbestos that have the potential to cause illhealth problems. The human factor includes human behaviour, competence and attitude; management such as leadership and safety culture of the organization. The job factors include the nature of the task, design detail, duration and the size of the structure itself.

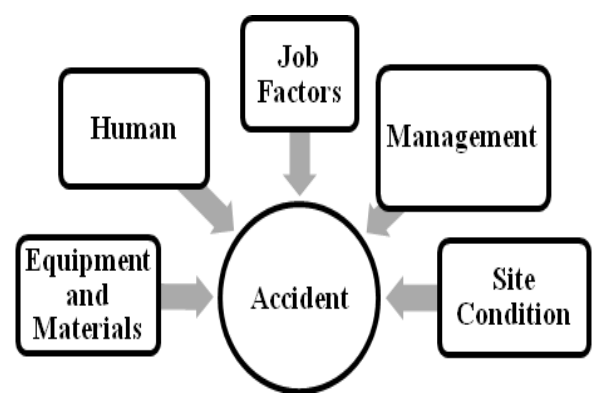

Fig. 1. Sources of health and safety risk on construction sites. Source: Okoye and Okolie (2014)

Lack of understanding of the job and poor equipment maintenance are also major causes of accidents. Injuries generally are unreported; however, if necessary, a siteoperative might receive first aid or preliminary medical care. In most cases, specialized medical treatment or compensation is unavailable. Workers themselves consider accidents as due 


\section{International Journal of Engineering Applied Sciences and Technology, 2021 \\ Vol. 6, Issue 4, ISSN No. 2455-2143, Pages 40-54 \\ Published Online August 2021 in IJEAST (http://www.ijeast.com)}

to their own negligence, and accept that construction is a dangerous occupation. Nevertheless, major accidents involving the death of a worker may be reported due to the financial expenses and litigation that could be involved (Okoye, 2010; Idoro, 2011; Guha, and Biswas, 2013).

\section{HEALTH AND SAFETY REGULATIONS}

Health and safety regulations governing the construction industry and other work related industries exist in Nigeria. A number of legislations on health and safety exist. These include;

1. Labour Act of 1974 modified to Labour Acts 1990, and updated to Labour Act, Cap L1, Laws of the Federation of Nigeria (LFN), 2004;

2. The Factories Act of 1987 which became effective in 1990 and later updated to Factories Act, Cap. F1, LFN, 2004 (FGN, 1990 and FRN, 2004);

3. The Workman's Compensation Act of 1987 which became effective in 1990, modified to Workman's Compensation Act, Cap W6, LFN, 2004 and repeal to Employee's Compensation Act, No. 13, 2010 of the laws of the Federation of Nigeria (FRN, 2010)

4. Labour, Safety, Health and Welfare Bill of 2012 including the National Building Code Enforcement Bill which has suffered huge political setback over the years.

In spite of numerous statutory provisions and expectations in Nigeria, gap still exist in health and safety. This problem is linked to adopting almost all existing regulations of reference on health and safety in Nigeria from foreign countries, especially from the British legal system with little or no changes made. Kolo (2015) observed that some provisions from these laws do not necessarily meet the conditions experienced in Nigeria.

According to researchers, effective risk management procedure is quite helpful in preventing and minimizing accidents and other ill health hazards, but it must be noted that accident prevention transcends beyond setting up risk assessment checklist, complying with safety rules and conducting of site safety inspection. What is paramount to a safe working environment is the development of a health and safety management system which meets the requirement of the industry and complies with stipulated regulation. The prevention of the accidents is the extreme goal of health and safety management systems, therefore, an efficient safety management system must be incorporated into all stages of industry decisions and processes.

\section{HEALTH AND SAFETY MANAGEMENT IN BUILDING AND CONSTRUCTION INDUSTRY}

Building and construction health and safety management system means the practices, procedures and resources for developing and implementing, reviewing and maintaining the industry's safety and health policy. A health and safety policy is a written document which recognizes that health and safety is an integral part of the building and construction industry performance. It is a statement by the industry of its intentions and approach in relation to its overall health and safety performance and provides a framework for action, and for the setting of its health and safety objectives and targets.

The health and safety policy must:

- Be appropriate to the hazards and risks of the industry's work activities and include a commitment to protect, as far as is reasonably practicable, its workers and others, such as contractors and members of the public, from health and safety risks associated with its activities.

- Include a commitment to comply with relevant $\mathrm{H} \& \mathrm{~S}$ legislation, Codes of Practice and guidelines, as a minimum.

- Provide a framework for measuring performance and ensuring continuous improvement by setting, auditing and reviewing $\mathrm{H} \& \mathrm{~S}$ objectives and targets.

- Be documented, understood, implemented and maintained at all levels of the organization.

- Clearly place the management of $H \& S$ as a prime responsibility of line management from the most senior executive level to first-line supervisory level.

- Cover employee H \& S consultation, safety committee meetings where they exist, worker participation and safety representation and includes a commitment to provide appropriate resources to implement the policy.

- Provide for employee co-operation and compliance with safety rules and procedures.

Although safety management systems have been implemented widely in construction organizations, the outcome has not been satisfactory and so the construction industry has recorded high rate of accidents and fatalities suffers from high occupational injury and fatality rates. This is as a result of poor health and safety management performance. Ulang (2012) identified six reasons for poor health and safety management performance. They are:

- limited knowledge of regulatory requirements,

- poor awareness of the economic advantages of health and safety, 


\section{International Journal of Engineering Applied Sciences and Technology, 2021 \\ Vol. 6, Issue 4, ISSN No. 2455-2143, Pages 40-54 \\ Published Online August 2021 in IJEAST (http://www.ijeast.com)}

- poor knowledge and understanding of safe working practices,

- short-term economic pressure and competition,

- inadequate enforcement and absence of preventive services, and

- limited resources.

\section{DUTIES OF PARTIES IN MANAGEMENT OF HEALTH AND SAFETY IN CONSTRUCTION INDUSTRY}

Health and safety is impacted on by various participants across the life cycle of a construction project. Decisions made at one stage in the life cycle also affect $H \& S$ at another stage further down in the life cycle, and key responsibilities at the various stages are to appoint participants that have the necessary competence and capacity in construction H\&S relevant to the project risks. Figure 2 below demonstrates the various process of the construction life cycle. Furthermore, H\&S performance is influenced by specification and communication of $\mathrm{H} \& \mathrm{~S}$ requirements from one participant to the others, and importantly on the effective monitoring of compliance with these expectations (Construction Industry Development Board, 2015).

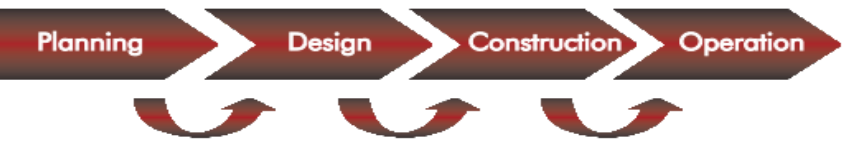

Fig. 2.Life Cycle of the construction process

Source: Construction Industry Development Board, (2015)

\section{A. The Client}

The philosophy of improving health and safety management starts with an obligation to establishing a team that will have the competence and resources to manage the project without any undue risk to health and safety. The client is increasingly being recognised as a key figure to drive effective health and safety practices within the construction industry, being the financier of the project; he has a major influence on what happens on a construction site.Client ensures workable organization of project, in terms of availability and provision of resources and enough time to deliver the project safely. A client is saddle with the responsibility to make available additional information as soon as is practicable to the designer and contractor appointed throughout the duration of the project.

The duties of the client includes:
- Appoint in writing, designer, planning supervisor or a CDM coordinator in the case of a mega project, a principal contractor and ensure that each of them have adequate training, knowledge, experience and resources to carry out their duties appropriately.

- $\quad$ Provide a copy of health and safety plan to every person tendering for the project. The health and safety plan documents how health and safety on the project will be managed up to project completion.

- Ensures that work does not commence on site until a comprehensive health and safety plan is in place.

- Ensures that a health and safety file is kept and updated on site and same is passed on to the future owner of project. Safety file contains information on the completed structure that will be required for future maintenance or renovation.

- $\quad$ Provides the health and safety file to anyone who requires it to comply with legal requirements.

- The Personal Protective Equipment Regulations require the client to provide without charges, clothing to protect the workers.

\section{B. The Designers}

$\mathrm{H} \& \mathrm{~S}$ information must be collected from the earliest point of the design stage. This is very important to eliminate, reduce and implement health and safety plan all through the design process, in order to see possibility of accident that may want to arise during production process of the project, maintenance and the habitation of the building upon completion. The investigation of $H \& S$ risks should be done as soon as the client approaches the designer with a project proposal. Therefore, it is very important to carry out a thorough site investigation and compile the $\mathrm{H} \& \mathrm{~S}$ information before the design starts to minimize the risks at any point.

Some clients have their own H\&S standards, but related to their business rather than construction. Therefore, it is crucial for the designers to communicate with these clients regarding the outline of $H \& S$ requirements and regulations for construction projects as many decisions must be made by the clients such as budget approval for $H \& S$ facilities, changes in design to coordinate H\&S information and so on.

The designers make sure that they are competent and adequately resourced to address the $H \& S$ issues likely to be involved in the design.

The designers must provide information about significant risks associated with the design and coordinate with others to 


\section{International Journal of Engineering Applied Sciences and Technology, 2021 \\ Vol. 6, Issue 4, ISSN No. 2455-2143, Pages 40-54 \\ Published Online August 2021 in IJEAST (http://www.ijeast.com)}

improve the way risks and hazards are managed and controlled.

- In order to produce a safe design, the designers have frequent interactions with team members to gain as much $\mathrm{H} \& \mathrm{~S}$ information as possible about the project.

- The architects, as the lead designers, bear the responsibility to ensure that the construction project can be carried out and maintained safely.

- Design risk assessments are carried out to highlight the potential risks and hazards.

- Communication will then expand to other designers such as structural and mechanical engineers.

- These engineers will enrich the drawings with necessary detailing, including the specification for H\&S aspects.

- They highlight the possible risks and put the appropriate details onto the drawings.

- Throughout the design process, regular meetings should be held among designers to produce a set of drawings that would, at best, eliminate the potential risks. In every meeting they include a subsection to discuss H\&S in that particular construction project.

- Ensure that the contractor retains all the H\&S documentation and uses it appropriately where necessary. This is to minimize and ideally eliminate all potential risks that would lead to fatal injuries

\section{Quantity Surveyors}

Quantity surveyors can have an unswerving influence on construction H\&S by, amongst others, drawing upspecifications that ensure that principal contractors have made adequate allowance for H\&S. However, previous studies revealed that quantity surveyors slightly have influence on the construction $\mathrm{H} \& \mathrm{~S}$ by preparing bills of quantities that provide sufficient allowance for $\mathrm{H} \& \mathrm{~S}$.

\section{Project Manager}

Provides review of all site activities and directs the activities via the Site Safety Officer, reports to Client.

\section{Responsibilities:}

- Prepares and organizes the background review of site conditions,

- Obtains permission for site access and coordinates activities with appropriate officials.

- $\quad$ Briefs the field team on their specific assignments.
- Coordinates with the Site Health and Safety Officer (SHSO) to ensure that health and safety requirements are met.

\section{i. Main Contractors}

Contractors, as the main players for a project in the construction phase, has the ultimate responsibility of ensuring a safe and healthy construction site. The roles of the main contractors at the production stage covers planning, managing, monitoring welfare facilities and coordinating health and safety of the site activities and ensure it implementation. Other important duties of the main contractor include:

- Setting up of H\&S as part of the company's strategic plan.

- Establishment of a robust top down commitment toward $\mathrm{H} \& \mathrm{~S}$.

- Provision of adequate funding to support the company's safety effort.

- Clearly spelt out instruction to the managers and supervisors on the level of H\&S standards expected on construction sites.

- H\&S programmes for the company must be properly resourced and staffed.

- Ensuring that all workers have been provided with suitable health and safety induction, information and training before the commencement of the job and also carry workers along on health and safety related matters.

- Ensure that all plants and equipment to be used on site are safe and used properly.

ii. Managers and Other Professionals:

In medium and large sized companies, contractors have their own management and professional personnel which comprises of project managers, engineers, estimators, designers, drafting technician, architects, financial managers and accountants. It is pertinent that these managers and professionals set positive examples by translating the contractor's commitment in health and safety into a daily practice by;

- Development of job description that enhances H\&S being a part and parcel of the every of employee/workers duties.

- Development of work procedures that emphasizes H\&S.

- Development of Performance Appraisal Form that contains H\&S criteria.

- Using safe work behaviours as part of company incentive and an important factor for promotion and pay raise. 


\section{International Journal of Engineering Applied Sciences and Technology, 2021 \\ Vol. 6, Issue 4, ISSN No. 2455-2143, Pages 40-54 \\ Published Online August 2021 in IJEAST (http://www.ijeast.com)}

- Effective communication of H\&S information to all employees and subcontractors

- $\mathrm{Be}$ in line with latest standards and regulation in the construction industry.

\section{iii Subcontractors}

The duties of the subcontractor are similar to those of the main contractor. The only difference is that the subcontractor might not need to create a new health and safety plan and even where this is the case, it must be consistent with principal contractor's health and safety corporate policy. The subcontractors are expected to participate in all relevant sections of the principal contractor's health and safety plan while they execute their duties on the project site. Subcontractors who execute their own independent of the main contractor must ensure that they can manage any risks arising out of their own work activity efficiently, establish control measures necessary to provide safe systems of work and provide information to their employees, including details of risk arising out of their work activity and cooperate with the main contractor.

\section{E. Supervisors}

This group of personnel play an important role in ensuring a safe and healthy job sites as they interact with siteoperatives more often than the first level of management or other professionals. The H\&S responsibilities of a supervisor are categorized into the following broad heading: training; accident prevention; accident investigation and reporting.

\section{i. $\quad$ Training Responsibilities}

The training could range from one-on-one conservation, group discussion to formal training. Irrespective of the medium used, it is important that training is appropriate for the operatives. The supervisor should provide:

- Orientation on the organisation policy and procedures.

- Proper use of equipment and handling of materials.

- Orientation on hazardous materials involved in the duties assigned.

- General housekeeping procedures

- Emergency procedures

\section{ii. $\quad$ Accident Prevention Responsibilities}

This is a continuous responsibility all through the construction phase of the project. The following various techniques could be adopted:
- Operatives should be empowered to identify hazards associated with their work and recommendations on how to minimize/reduce such risk.

- Supervisor and operatives should work as a team in developing safe work procedures.

- Operatives should be tutored on appropriate use of personal protective equipment and they should also be taught the fundamentals of safe working practices

- Despite aforementioned techniques, the supervisor must still monitor closely every activity of operatives to ensure that it is in compliance with required health and safety standards.

\section{iii. Accident Investigation and Reporting}

Despite all the above mentioned preventive efforts by the supervisor, accident may still occur. When this happen, supervisor must investigate the accident with aim of preventing the likely occurrence of the same accident another time. It is important that the investigation is carried out immediately as time can obscure facts, witnesses can forget, unrelated factor can creep in, accident scene can change to obscure what really happened. Once the investigation is conducted, an accident report shall be written. Regardless of the format adopted by the supervisor, the following rules should be ensured.

- The report should be brief and contain facts of the incidence.

- The supervisor must be objective and impartial.

- State clearly what operative(s) and equipment were involved.

- List any procedure, process or precaution that were not observed as at the time of the accident.

- List any casual or contributing factor

- Make clear and concise recommendation for corrective measures.

\section{F. Site Health and Safety Officer (SHSO)}

Advises the Project Manager on all aspects of health and safety on site. Stops work if any operation threatens worker or public health or safety.

\section{Responsibilities:}

- Manages field operations.

- Enforces safety procedures.

- Ensures that all necessary Health and Safety equipment is available on site and is functional.

- Periodically inspects protective clothing and equipment. 


\section{International Journal of Engineering Applied Sciences and Technology, 2021 \\ Vol. 6, Issue 4, ISSN No. 2455-2143, Pages 40-54 \\ Published Online August 2021 in IJEAST (http://www.ijeast.com)}

- Ensures that protective clothing and equipment are properly stored and maintained.

- Controls entry and exit on the site.

- Coordinates health and safety program activities.

- Confirms each team member's suitability for work based on a physician's recommendation.

- Monitors the work parties for signs of stress, such as cold exposure, heat stress, and fatigue.

- Conducts periodic inspections to determine if health and safety regulations are being followed.

- Knows emergency procedures, evacuation routes, and the telephone numbers of the ambulance, local hospital, fire department, and police department in the event of an emergency.

- Coordinates emergency medical care.

- Ensures that all required equipment is available.

- Assist in the preparation of all Root Cause Investigation Reports/ Preventative Action Plans for any incidents.

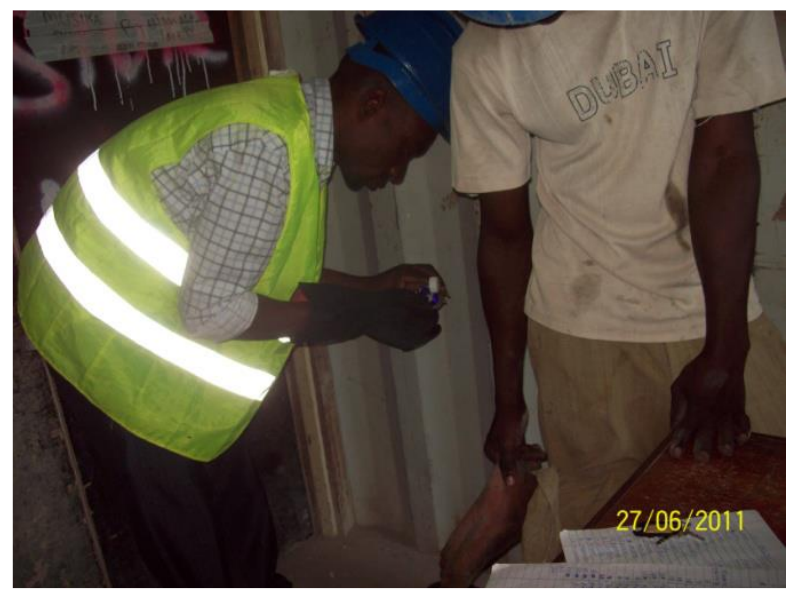

Fig. 3. Safety Officer Providing First-Aid to the Injured Workers

\section{G. Site-operatives}

The concerted effort of main contractors, managers, professionals, supervisors and subcontractor will not be sufficient to prevent accident from occurring on construction sites without great commitment on the part of operatives irrespective of whom their boss is, be it the main contractor or subcontractors. They must be carry along on any issue related to their health, safety, and welfare. The operatives take responsible for their health, safety and that of their fellow colleagues. They give the contractor feedback on anything that may affect their health and that of the coworkers.
It is quite pertinent that the operatives do not only know the rules but also adhere strictly to them as the provision of prescriptive procedure and processes are not enough to guarantee safe behaviour in the workplace. It requires a culture change that relies on a continuous and long term commitment to understanding, evaluating and improving construction activities and processes. The operatives' responsibilities in terms of health and safety include;

- To be mindful of their own health and safety.

- To work in harmony with other persons on site to achieve common goal.

- To avoid putting fellow employees and members of the public at risk for what they choose or fail to do in the course of executing their duties.

- To adhere to company's health and safety policies and procedures.

- To report any injury or illnesses suffering at workplace.

For construction industry to record outstanding changes in the rate of accidents, diseases injury and ill health on construction sites, the industry must not surrender its effort by constantly using various means (partnership, inspection, investigation, enforcement and prosecution) to ensure a safe work environment for all the operatives.

\section{COMMUNICATION OF HEALTH AND SAFETY AMONG THE PARTIES INVOLVED IN CONSTRUCTION}

Findings from studies carried out to assess the causes of accidents have all pointed to poor communication of health and safety information among all the parties involved in construction activities (Landin and Kindahl, 2013; Kwofie, 2015; Akunyumu, 2016, Adebiyi, 2018). Communication of health and safety has been regarded to be a focal point for reducing accidents and ill-health problems on construction sites (Phoya, 2012). Communication does not only helps people to maintain good relationship, improves teamwork, enables better collaboration but also keeps people updated on organizations' health and safety policies and regulations, the use of personal protective equipment, warning about disasters, first aid procedures and how to manage emergencies. According to Zulch (2012), communication in the construction industry is of maximum importance irrespective of the fact that projects are planned, organized and managed by experienced and qualified personnel. Communication educates construction participants on how to achieve safe working environment by giving and receiving information about hazards and risk controls. Many researchers emphasized that the quality of the communication experienced on 


\section{International Journal of Engineering Applied Sciences and Technology, 2021 \\ Vol. 6, Issue 4, ISSN No. 2455-2143, Pages 40-54 \\ Published Online August 2021 in IJEAST (http://www.ijeast.com)}

construction projects is crucial to attaining acceptable level of efficient and effective health and safety (Ahadzie, Proverbs and Sarkodie-Poku, 2014).

Effective communication about health and safety relies on information coming intothe organization, flowing within the organization and going out from the organization.

A. Information Inputs -: Good sources of health and safety intelligence are as important in developing health and safety policy and performance as market information is for business development. Organizations need to monitor legal developments to ensure they can comply with the law, technical developments relevant to risk control and development in health and safety management practice.

B. Information Flows within the Organization -:If the health and safety policy is to be understood and consistently implemented, the following key information needs to be communicated effectively: the meaning and purpose of the policy; the vision, values and beliefs which underlie it; the commitment of senior management to its implementation; plans, standards, procedures and systems relating to implementation and measurement of performance. Others include: factual information to help secure the involvement and commitment of employees; comments and ideas for improvement; performance reports; lessons learned from accidents and other incidents.

C. Information Flow from the Organization -:Organizations may need to pass health and safety information to others, including: accident or ill health information to enforcing authorities; information about the safety of articles and substances supplied for use at work and emergency planning information.

Therefore, safety on construction sites relies on effective communication of health and safety information between individuals, teams and organizations

\section{STRATEGIES FOR COMMUNICATION OF HEALTH AND SAFETY}

For health and safety information communication to be effective it has to be understood, which is governed by kind of information to be communicated, the target audience and the strategy used. The communications strategy serves as a recommended framework and action plan for an organization's communications and outreach efforts. VecchioSadus (2007) in his study, acknowledged that different strategies are required for different organizations and deciding the effectiveness of communication of health and safety information depends on the strategy used. This strategy will influence whether people will understand or not and participate in the safety process. The language used often determine its effectiveness.

Some of the following strategies can be used for communication of health and safety information:

A. Organization Mission Statement, Policy and Strategic Plan-: Organization mission statement and policy assist to define and communicate the direction of the health and safety process and will provide a reference for making organization decisions. Organization strategic plan communicates the objectives and priorities that are aligned with the overall health and safety plan.

B. Safety Induction-: Health and safety information can be communicated through induction by practitioners and supervisors on site rules and requirements, emergency procedures and incident reporting to enable new employees, visitors and contractors to carry out their duties in a safe manner from the moment they come on site.

C. Manuals, Checklists and Operating procedures-: An organization's safety manual consolidates the rules and requirements for working safely. Manuals communicate more specific safety information such as how to operate machinery, accident reporting and dealing with emergency situations. Checklists are used as checking tools or guidelines to help in operating equipment and making informed decisions about operation. Operating procedures provide advice on acceptable and safe work practices. The lock-out or tag-out of faulty equipment or work in progress on sites can communicate potential danger.

D. Reports of Hazards, Incidents and Near-Misses-: Communicating the reports of a hazard or incident investigation demonstrates management commitment in identifying and addressing underlying causes to prevent a recurrence. The involvement of employees in suggesting strategies to prevent a recurrence encourages ownership of the solution(s) and a desire to implement the recommendations. According to Zulch (2012), it is important to have on-going campaigns to encourage the reporting of incident and injuries as many employees will not report for fear of recrimination. Reporting near-misses ensures remedial actions are implemented prior to incident causing injury or ill health.

E. Training-: Training consist of instruction in hazard recognition and control measures, learning safe work practices and proper use of personal protective equipment, acquiring knowledge of emergency procedures and 


\section{International Journal of Engineering Applied Sciences and Technology, 2021 \\ Vol. 6, Issue 4, ISSN No. 2455-2143, Pages 40-54 \\ Published Online August 2021 in IJEAST (http://www.ijeast.com)}

preventive actions. Training also provide workers with ways to obtain added information about potential hazards and their control; they could gain skills to assume a more active role in implementing hazard control programs or to effect organizational changes that would enhance worksite protection. Training in safe work methods should involve raising employee's awareness of their true values towards health and safety, include being able to work without injury so they can continue to provide for their family.

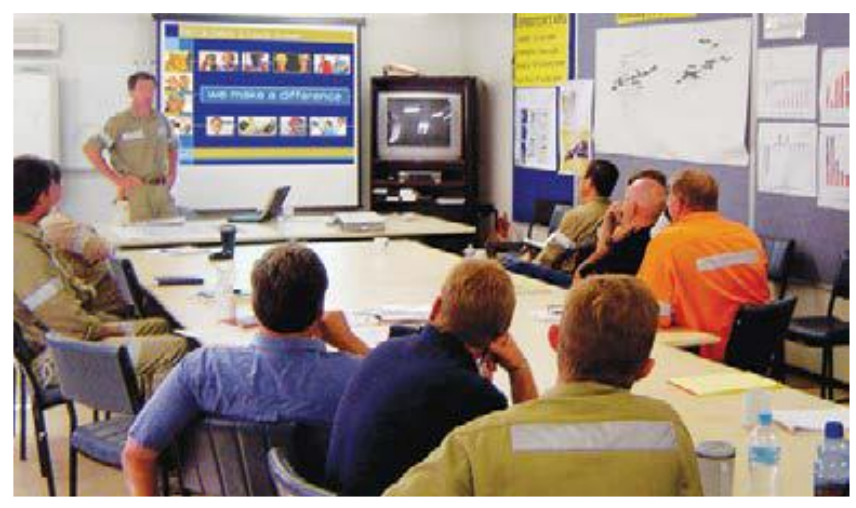

Fig 4. Site-operatives undergoing training on health and safety

F. Health and Safety Website-: With a vast amount of information available, it is essential that the critical information on health and safety is readily accessed and understood. A health and safety intranet can provide a one-stop shop that includes the safety manual, policies and fact sheets. The resources must always be available to keep the workforce informed so they are better able to respond to changing risk and to prevent incidents and injuries. For Health and safety website to be effective, people need to know of its existence, they need to be motivated to access the information and the information needs to be updated regularly.

G. Brochures, Posters and Notice Boards-: A wide variety of publications on health and safety matters are available in form of brochures or organization's in-house newsletter. Small instructional leaflets can also be suitable for general distribution. All these should be printed in several languages if the workforce is multicultural. Posters therefore, overcome language problems through the use of illustrations and symbols. To maintain attention, posters should be kept on a special display board. Notice boards transmit information of short-term importance such as general safety performance, hazard refresher information, accident and incident report summaries, procedure updates, minutes of safety review meetings and safety inspection reports. Notice boards should not be used to display detailed procedures, as they will not be read. It is very important to update notice boards by removing obsolete materials.

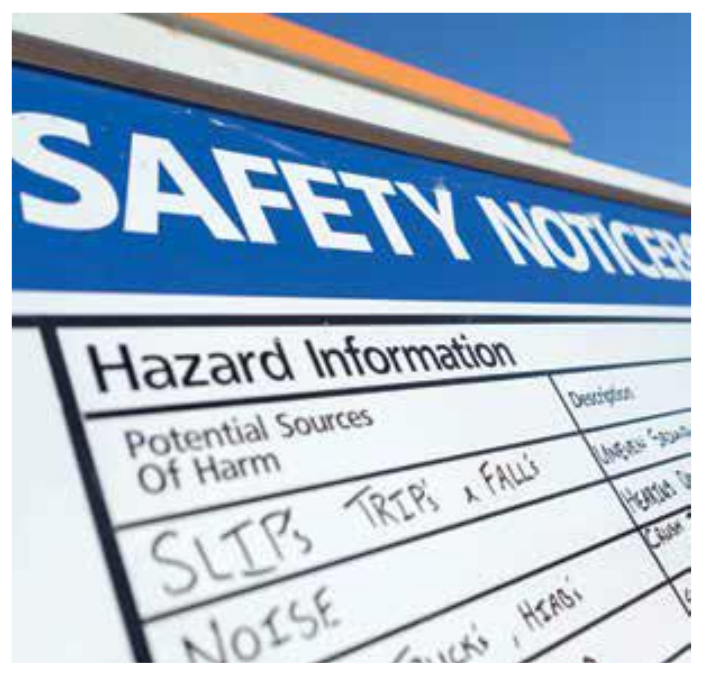

Fig 5. Safety Notice Board

H. Health and Safety Warning Signs-: Safety Signs and Signals are one of the main strategies of communicating health and safety information. This includes the use of illuminated signs, hand and acoustic signals (e.g. fire alarms), spoken communication and the marking of pipe work containing dangerous substances. Traditional signboards, such as prohibition and warning signs, signs for fire exits, fire action plan notices (fire drills) and firefighting equipment are also considered to be safety signs. It is critical that all safety signs and signals can be easily understood.

Where signboards are used in a workplace they should be sufficiently large and clear so that they can be easily seen and understood. Signboards also need to be durable, securely fastened and properly maintained to ensure they remain visible. Care must be taken to avoid using too many signboards in close proximity, signboards are only effective if they can be seen and understood. If too many signs are placed together there is a danger of confusion or of important information being overlooked 

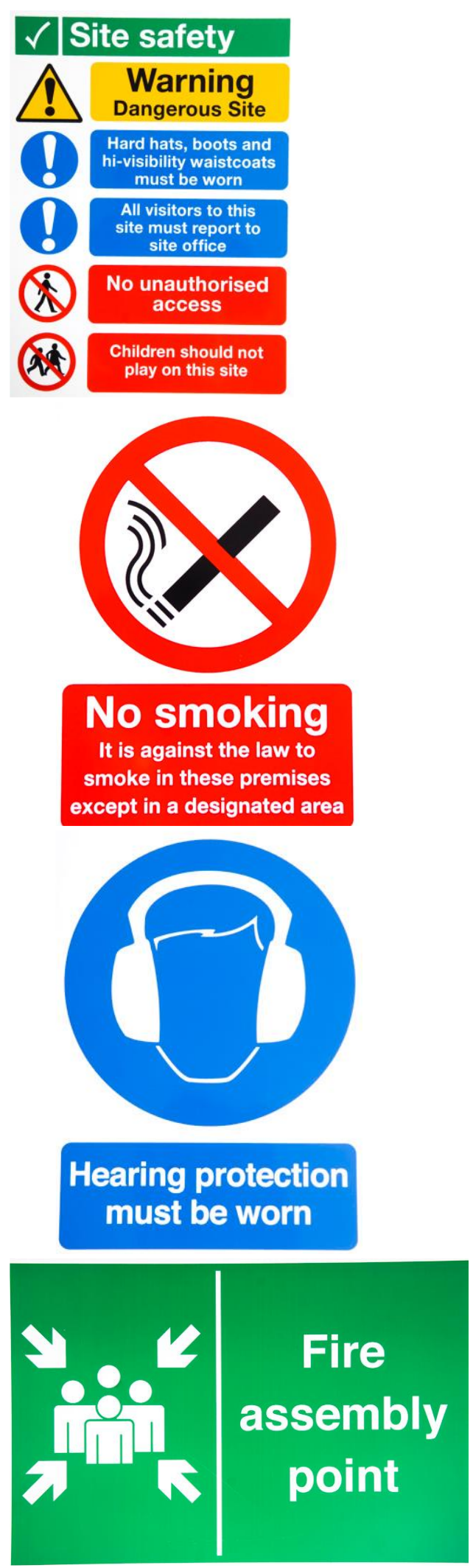
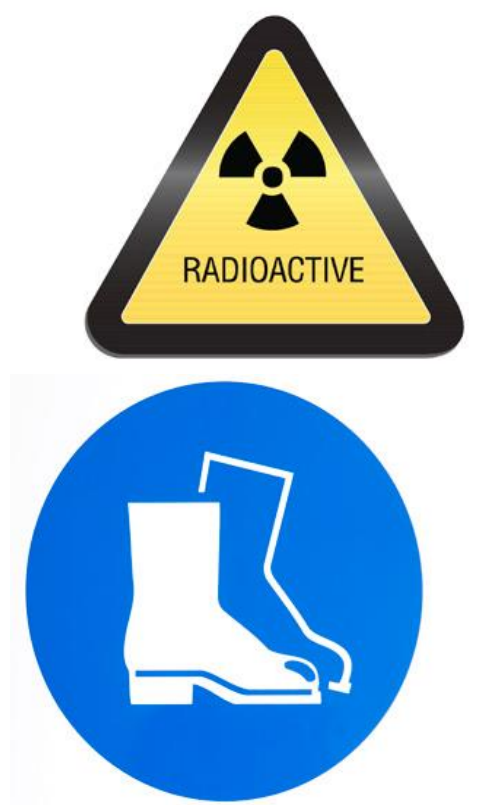

Fig. 6 Standard Health and Safety Signs on Construction Sites

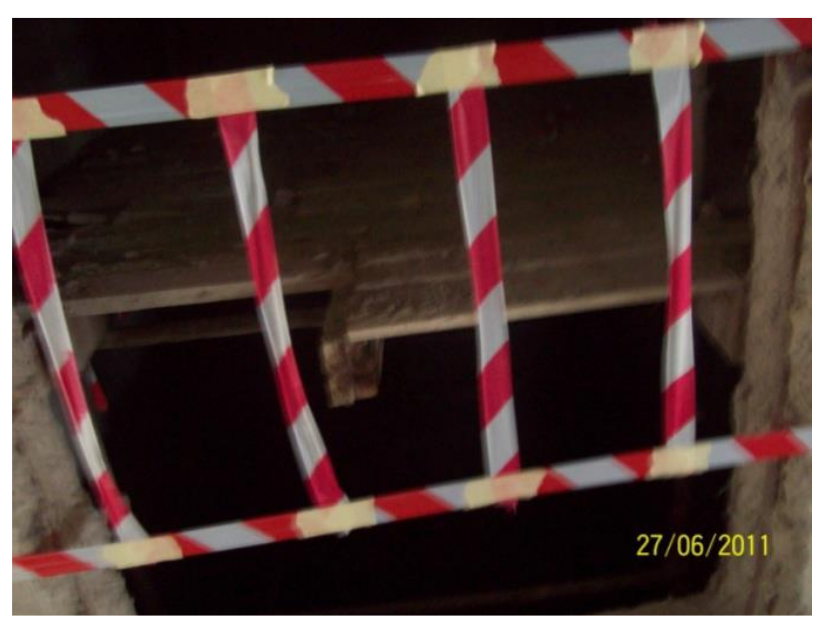

Fig 7 Warning Tape Showing there is an Open Hole

I. Toolbox Talks-: Toolbox health and safety talks are a common way to remind workers about safety procedures. When foremen gather workers at the beginning of a shift to talk about the day's work, they should review the hazards involved and the safety controls, and make sure that the workers have the right protective gear and that all safety concerns are addressed. Monthly site meetings should include a review of any accidents, near misses or safety lapses as well as safety issues related to the coming work 


\section{International Journal of Engineering Applied Sciences and Technology, 2021 \\ Vol. 6, Issue 4, ISSN No. 2455-2143, Pages 40-54 \\ Published Online August 2021 in IJEAST (http://www.ijeast.com)}

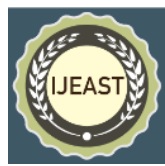

appropriate for particular circumstances. It is important to first

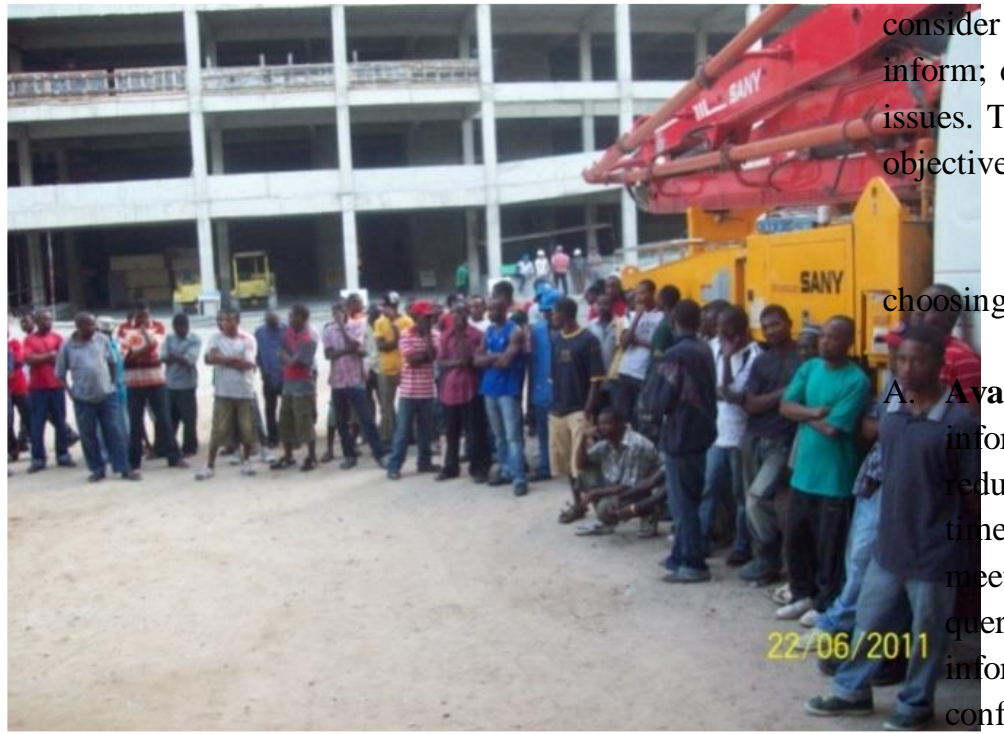

der the objective of communication i.e. to persuade; m; question or instruct the workers on health and safety This will now be tailored to the strategy that suits the

The followings are the factors to be considered in g a communication strategy that will be most suitable.

ailability of Time/Time pressures-: Health and safety ormation needs to be provided as quickly as possible to luce associated costs and losses of productivity. Much e are required to organize health and safety training, eting and conference, including time to respond to eries. Due to urgency in the need of health and safety ormation limited numbers of safety meetings, ference and training may be organized.

Fig 8. Site-operatives listening to at the Toolbox Meeting

J. Health and Safety Week-: Health and safety week aims to promote a happier and healthier workplace by raising the level of awareness amongst employees, and demonstrating commitment from management. Such events provide an excellent opportunity to showcase health and safety at its best. Activities can include health and safety conference, seminars, health checks (e.g. cholesterol test, blood pressure check, hearing test, etc). Recognition of good safety performance by presenting safety awards, safety performance appraisals and organizing social event with a safety theme can also demonstrate management safety commitment.

K. Public Report-: Many companies report on health and safety in annual Health and Safety Report that illustrates the range of activities and initiatives undertaken along with a review of performance standards achieved. Reporting health and safety in an annual report helps to demonstrate an organization's commitment, achievements, in workplace safety and employee welfare.

In order to improve on health and safety of workers on construction sites, parties involved need to pay attention to the choice of communication strategies to be used on the sites.

\section{FACTORS INFLUENCING THE CHOICE OF COMMUNICATION STRATEGIES FOR HEALTH AND SAFETY}

Strategies of communications of health and safety information can take many different forms, with each being
B. Literacy Skill of Site Operatives-: For the operatives with little or no understanding of English language, or who cannot read the language, employers may need to make special arrangements. These could include providing translation, using interpreters, or replacing written notices with clearly understood symbols or diagrams. An increasingly popular method of conveying health and safety messages to a wide multilingual audience is by visual means. Traditionally, training material in health and safety has been enhanced by the use of cartoons in manuals and graphic videos showing accidents to help get the message across to usually unresponsive groups of workers.

C. Awareness of Information Technology-: In recent years there has been a revolution in the development of Information Communication Technology (ICT). Electronic forms of communication, such as email and web-based tools, are now commonplace in virtually all industries and sectors. The take-up of these types of technology has been particularly rapid because of the advantages that they present in speeding up the rate of communication between parties and transferring information between parties. Digital technology facilitates the capturing of site-related images, quickly transferring these into posters or other media to communicate the message in a very relevant way.

D. Number of Recipients-: Organizations require different strategies to communicate to their employees which are contingent upon their size. Communication needs of a very small (or micro) sized construction firm focusing on very few workers will be markedly different from a large 


\section{International Journal of Engineering Applied Sciences and Technology, 2021 \\ Vol. 6, Issue 4, ISSN No. 2455-2143, Pages 40-54 \\ Published Online August 2021 in IJEAST (http://www.ijeast.com)}

organization operating globally with large numbers of workers.

E. Types of Information/Message-: Simple health and safety messages can be conveyed orally through one-toone interaction or at group meetings - complex messages need supporting documents, and significant messages may need reminders, e.g. a memo. This decision will be to some extent governed by the need for formality; informal messages are best communicated by informal means and vice versa.

F. Nature of hazard/severity of the risks involved-: Methods of communication of health and safety information on identified hazards or risks on construction sites should be established clearly and agreed upon by all stakeholders. Any deviations from the prescribed strategy of communication could result in messages not being received by the intended parties in a timely manner causing delays in the project.

G. Cost Implication of the Strategy-: If the workforce is diverse and speaks different languages, management may need to translate the information. The use of qualified translators who understand the industry will be required. Translations can be expensive, particularly if the information needs to be updated regularly. If possible, translation service must cover all the relevant language groups. All translations should ideally be checked for clarity and accuracy by a native speaker before use.

\section{CONCLUSION}

The paper identified the important contribution of building and construction industryto national economy. Despite the importance, the industry is regarded as one of the most hazardous place to work because of frequent occurrence of accidents and ill health on construction sites which usually lead to direct and indirect loss. These have necessitated theneed for aneffective health and safety management in the industry by involvement of all parties concerned. Communication among these parties is of maximum importance irrespective of the fact that projects are planned, organized and managed by experienced and qualified personnel. Communication educates them on how to achieve safe working environment by giving and receiving information about hazards and risk controls. For health and safety information communication to be effective it has to be understood, which is governed by the strategy used. The paper therefore, recommended that all the parties involve in construction should contribute their efforts to mitigate accidents and ill health. However, construction industry health and safety management should not be seen as a luxury, but be considered as an important function to be used against unnecessary occurrence of accidents, ill health and loss of resources (human and materials). So therefore, it should be the primary concern of all the parties involved.

\section{REFERENCES}

1) Adebiyi, R. T. (2018) Assessment of health and safety information communication on construction sites in Lagos State, Nigeria. Unpublished PhD thesis Submitted to the Department of Quantity Surveying, Obafemi Awolowo University, Ile-Ife, Nigeria

2) Agwu, M. O. and Olele, H. E. (2014). Fatalities in the Nigerian Construction Industry: A case of Poor Safety Culture. British Journal of Economics: Management and Trade, 3 (4), 431-454.

3) Ahadzie, D., Proverbs D. and Sarkodie-Poku, I. (2014) Competencies required of project managers at the design phase of mass housing building project. International Journal of Project Management. 32 (6), 958-969.

4) Akunyumu, S. (2016) A framework for on-site communication planning for construction managers in Ghana. Unpublished thesis Submitted to the Department of Building

Technology, College of Art and Built Environment, Kwame Nkrumah University Of

Science and Technology, Kumasi, Ghana.

5) Alhajeri, M. (2011) Health and safety in the construction industry: challenges and solutions in the UAE. Unpublished PhD in Civil Engineering thesis submitted to University of Coventry.

6) Baldacconi, A., and Santis, P.D. (2000). Risk Assessment in Construction Field in Italy.

National Institute for Insurance against Injuries at Work. Rome, Italy.

7) Dadzie, J. (2013) Perspectives of consultants on health and safety provisions in the Labour Act: A study into theory and practical. Journal of Engineering Management Research 2 (1)34-42.

8) Dansoh, A. (2005). Strategic planning practice of construction firms in Ghana. Construction Management and Economics, 23(2), 163-168. 


\section{International Journal of Engineering Applied Sciences and Technology, 2021 \\ Vol. 6, Issue 4, ISSN No. 2455-2143, Pages 40-54 \\ Published Online August 2021 in IJEAST (http://www.ijeast.com)}

9) Ezenwa A. O. (2011) A study of fatal injuries in Nigeria factories. Occupational medicine 5 (8) 485592

10) Guha, H. and Biswas, P. (2013). Measuring construction site safety in Kolkota, India International Journal of Scientific and Engineering Research. 4 (5) 2138-2143.

11) Holt A. S. (2001) Principles of Construction Safety, Oxford Blackwell Science.

12) Idoro, G. I. (2011) Comparing Occupational Health and Safety (OHS) Management Efforts and Performance of Nigerian Construction Contractors. Journal of Construction in Developing Countries. Preview Manuscript.

13) Idoro, G. I. (2008) Health and safety management efforts as correlates of performance in the

Nigeria construction industry. Journal of Civil Engineering. 6 (23), 75-83.

14) International Labour Office (ILO). (2005) Global estimates of fatal work related diseases and occupational accidents, World Bank Regions. International Labour Organisation, Geneva.

15) Kadiri Z.O., Nden T., Avre G.K., Oladipo T.O., Edom A., Samuel P.O., Ananso G.N. (2014)

Causes and effects of accidents on construction sites (a case study of some selected

construction firms in Abuja F.C.T Nigeria). Journal of Mechanical and Civil Engineering

11(5) PP 66-72

16) Kheni A. (2008) Impact of Health and Safety Management on Safety Performance of Small and Medium-sized Construction Businesses in Ghana, Doctorial Thesis, Loughborough University, UK

17) Kolo D. N. (2015) Safety issues involving workers on building construction sites in Nigeria: An Abuja study. Master of Science Thesis in Civil Engineering, Eastern Mediterranean University, Gazimağusa, North Cyprus

18) Kwofie, E. (2015). Contribution of Unique Features of Mass Housing Projects to Project Team Communication Performance. Kwame Nkrumah University of Science and Technology, Department of Building Technology. Kumasi, Ghana: Unpublished PhD Thesis.

19) Landin, E., and Kindahl, N. (2013). Information and communication trends in the Swedish construction industry. KTH Architecture and the Built Environment, Department of Real Estate and Construction Management, Stockholm.

20) Laryea, S., and Mensah, S. (2010). Health and safety on construction sites in Ghana. COBRA. Dauphine Université, Paris, 2-3 September 2010.

21) Muiruri G. and Mulinge, C. (2014) Health and safety management on construction projects sites in Kenya, A case study of construction projects in Nairobi country. International journal of Occupational Safety, Environmental Health3(3), 50-61

22) Okoye, P. U, (2010) The Influence of National Culture on Workers Safety Climate in the Nigerian Construction Industry. Unpublished M.Sc Thesis, Department of Building, Faculty of Environmental Sciences, Nnamdi Azikiwe University, Awka.

23) Okoye, P. U. and Okolie, K. C. (2014), Exploratory study of the cost of health and safety

performance of building contractors in south- east Nigeria. British journal of Environmental sciences 2 (1), 21-33

24) Phoya, S. (2012). Health and safety risk management on building construction sites in Tanzania: the practice of risk assessment, communication and control. An unpublished master thesis submitted to Chalmers University of Technology

25) Rahim A., Hamid, A., Zaimi M., Majid,A. and Singh, B. (2008) Causes of Accidents at

Construction Sites. Malaysian Journal of Civil Engineering 20 (2), 242-259.

26) Ulang, N. M. (2012) Communication of construction health and safety information in design. Journal of Civil and Environmental Research. 2 (5), 25-33

27) Umeokafor, N. I. Isaac D. Jones K.G. and Umeadi B. (2014) Enforcement of occupational safety and health regulations in Nigeria: An exploration. European Scientific Journal, Special Edition, 3, 93104. 
International Journal of Engineering Applied Sciences and Technology, 2021

Vol. 6, Issue 4, ISSN No. 2455-2143, Pages 40-54

Published Online August 2021 in IJEAST (http://www.ijeast.com)

28) Veccio- Sadus, A. M. (2007) Enhancing safety culture through effective communication. Journal of Safety Science Monitor 3 (2), 34-41

29) Zulch, B. G. (2012). The Construction Project Manager as Communicator in the Property

Development and Construction Industries. $\mathrm{PhD}$ Thesis, University of the Free State. 